\title{
An Analysis of Grammatical Metaphor of Oscar-Winning Film Titles
}

\author{
Zhenghua $\operatorname{Tan}^{1, \mathrm{a}^{*}}$ and Yiting $\mathrm{Wu}^{2, \mathrm{~b}}$ \\ ${ }^{1}$ School of foreign languages, Jianghan University, Wuhan, Hubei Province, China \\ a1548297043@qq.com, b1753270552@qq.com
}

\begin{abstract}
Keywords: Grammatical metaphor; Nominalization; Film titles; Translation strategies
\end{abstract}
\begin{abstract}
Grammatical Metaphor is an incongruent expression in realization of meaning on lexical and grammatical level, of which the main form is nominalization. It is divided into ideational metaphor and interpersonal metaphor. By analysis of the titles of thirty American Oscar-winning films, it can be found that nominalization is a common phenomenon. Based on this, the English film titles discussed may enlighten the Chinese film titles translation in cross-cultural communication and nominalization should be a tendency of expression form when translating Chinese film titles into English, in order to convey information of them more concisely and efficiently.
\end{abstract}

\section{Introduction}

During the increasingly frequent cross-cultural communication, more and more Chinese films have access to enter foreign film markets. According to the statistics, the production of Chinese feature films up to 686 while the imported films are only 63 in 2015. Moreover, the sale of Chinese films abroad is 2.77 billion Yuan, up $48.13 \%$ over last year. Thus it can be seen that export of films will become a trend in the future. Considering this, film translation plays a fairly important role. And title translation comes first when films are faced with overseas propaganda. It is generally known that a title is the soul of a film. It is the epitome and highlight of the content of a film, making viewers generate the desire for watching it. So the translation of a title is vital to the success of a film.

The theory of grammatical metaphor was developed by Halliday in his book An Introduction to Functional Grammar in 1985. "If something is said to be metaphorical, it must be metaphorical by reference to something else. This is usually presented as one-way relationship such that to some metaphorical meaning of a word there corresponds another, non-metaphorical meaning that is said to be literal" (Halliday, 2000:342). He held that, as a system of social semiotic, language consists of expression level and meaning level, which show respectively in lexical and grammatical form and semantic form.

Researches on grammatical metaphor have been published at home as well as abroad. Foreign scholars such as Halliday, Martin, Matthiessen and Goatly comprehensively elaborate this theory, some of whom even extended the research mode of Halliday. They introduced new classifications of grammatical metaphor, studied the relationship between grammatical metaphor and ideology, or discussed the connection between that and register and so on. Meanwhile, many Chinese scholars also had much concern about it and devoted most of their efforts to theory introduction and exposition in detail, including its classifications, reasons for emerging, forms of realization, philosophical significance and other aspects (Zhang and Dong, 2014:32). In addition to this, researches on application of grammatical metaphor theory in English language teaching, translation and discourse analysis also take a large proportion. Main concentration is on journalistic English and technical English regarding translation. For example, Liu chenhong considered that changing the form of language through grammatical metaphor will accentuate the impact of language, which is what journalistic language needs ( $\mathrm{Liu}, 2011: 61$ ). $\mathrm{Xu} \mathrm{Wu}$ proposed that ideational metaphor contributes to the formality, brevity and objectivity known as the stylistic features of scientific and technical text, and it provides an easy way for translating this kind of text (Xu, 2008:38). 
However, there is few study on film translation especially title translation based on the theory of grammatical metaphor. As a branch of literary translation, the study of film title translation is theoretically necessary.

\section{The Theory of Grammatical Metaphor}

\section{Ideational Metaphor and Interpersonal Metaphor}

Ideational Metaphor. The section headings are in boldface capital and lowercase letters. Second level headings are typed as part of the succeeding paragraph (like the subsection heading of this paragraph). Halliday points out that ideational metaphor refers to the transitivity of ideational function which means one process can be metaphoried to another process (Ren, 2011:139). For example:

(1).On the fifth day they arrived at the summit.

(2). The fifth day saw them at the summit.

"It is held that transitivity whose role is to divide what people saw and heard in the real world into several kinds of "process" belongs to a semantic system. That is to say, transitivity categorizes experience via grammar, and points out "participant" and "environment component" which related with the processes. Halliday holds that human experience can be divided into six different processes through the transitivity systems: 1) physical process; 2) mental process; 3 ) relative process; 4) behavior process; 5) speech process; 6) existence process. Transitive processes can be transformed into each other, with one process metaphoried the other process. As the process of conversion goes, the functional components of clauses (participants, processes and environmental factors, etc.) can be metaphoried into each other, and the converted part can also be metaphoried from to the other in the word grammatical level" (Wang and Zhang, 2012:259).

Interpersonal Metaphor. In Halliday's Systemic Functional Grammar published in 1985, "The grammar also accommodates metaphors of an interpersonal kind, in the expression of mood and modality" (Halliday, 2000:354).

The mood is composed of the subject of the clause, the finite (which indicates grammatical number, primary tense and modality), polarity markers, and modal adverbs. In this conception, it is the mood element that plays a part of the utterance as an interactive event, and therefore, the interpersonal component is manifested in language through the mood element. The different systems about options that are realized in the mood element are stated on two different levels: the level of speech functions and the level of mood and modality.

Nominalization. Halliday points out nominalization is the most powerful resource to construct ideational metaphor. Nominalization means the use of a word which is not a noun (e.g. a verb indicating process, or an adjective indicating attribute) as a noun, or as the head of a noun phrase, with or without morphological transformation. In other words, it is nominalization that turns verbs and adjectives in congruent form into nous or noun phrases in metaphorical form, which rebalances the information structure of sentences and discourses by the changes of participants and environment components. For instance:

(3)She danced elegantly in Chinese way. (Congruent form);

(4)She did an elegant Chinese dance. (Metaphorical form).

It can be easily seen that the verb "dance" showing a process of an action in (3) converts to "did an elegant dance" which is a noun form. Usually, (3) is what has been chosen first to express a process, which is so-called congruent form, while (4) is in a noun form with grammatical metaphor, which is co-called metaphorical form. Nominalization concentrates as much information as possible on a brief expression, making sentence structure more compact, achieving objectivity carried by sentences.

"It made it possible on the one hand to construct hierarchies of technical terms, and on the other hand to develop an argument step by step, using complex passages "packaged" in nominal form as Themes" (Halliday, 2000:353). 


\section{American Oscar-Winning Film Titles}

Nominalization in Oscar-Winning Film Titles. There are 30 American Oscar-winning film titles chosen from 1956 to 2015 with high awareness, and most many people are familiar with, including all kinds of types. It can be found that some of these titles are only single words, some are phrases while the left are sentences by close observation. According to this, classifying them into different groups is in order to make their characteristics more apparent. Specific classifications and statistics are as follows:

Table 1 Classification of Various Expressive Types in 30 Oscar-Winning Film Titles

\begin{tabular}{|c|c|c|c|}
\hline Type & English Title & Total & Percentage \\
\hline Noun & $\begin{array}{l}\text { Birdman } \\
\text { Argo } \\
\text { Chicago } \\
\text { Titanic } \\
\text { Casablanca } \\
\text { Forrest Gump }\end{array}$ & 6 & $20.0 \%$ \\
\hline Noun Phrase & $\begin{array}{l}\text { The Godfather } \\
\text { The Departed } \\
\text { The Artist } \\
12 \text { Years a Slave } \\
\text { The King's Speech } \\
\text { Schindler's List } \\
\text { The Hurt Locker } \\
\text { Slumdog Millionaire } \\
\text { The Lord of the Rings: The Return of the King } \\
\text { The Sound of Music } \\
\text { The Silence of the Lambs } \\
\text { A Beautiful Mind } \\
\text { American Beauty } \\
\text { The English Patient } \\
\text { Brave Heart } \\
\text { My Fair Lady } \\
\text { Shakespeare in Love } \\
\text { Dances with Wolves } \\
\text { No Country for Old Men }\end{array}$ & 19 & $63.3 \%$ \\
\hline Adjective Phrase & Gone with the Wind & 1 & $3.3 \%$ \\
\hline Prepositional Phrase & $\begin{array}{l}\text { Out of Africa } \\
\text { In the Heat of the Night } \\
\text { Around the World in Eighty Days }\end{array}$ & 3 & $10.0 \%$ \\
\hline Sentence & One Flew over the Cuckoo's Nest & 1 & $3.3 \%$ \\
\hline
\end{tabular}

\section{Diagram 1 Proportion of Each Type in Table 1}

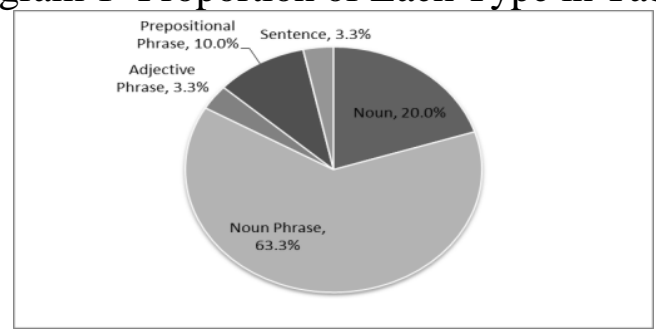

A quick look at this form above indicates that noun phrase used in titles is the leading part, followed by single noun form, which means nominalization takes up a large proportion, and adjective phrase, prepositional phrase, sentence forms make up only $16.6 \%$ altogether.

Throughout these 30 cases selected, some features here are very clear. First and foremost, in terms of the form, noun and noun phrase are the most common choice of representation in American Oscar-winning film titles, which is called nominalizing metaphor in grammatical metaphor theory as 
mentioned above. Other forms except for noun and noun phrase take up only a small proportion showing a rare use of them in film titles. Second, in terms of the length of these titles, all of them are no more than 6 words and the shortest is just one word, impressing a short, concise but focused style with main character or idea highlighted at a glance. Third, nominalization seems to become more and more common in English movies. There are 8 titles selected during recent ten years and all of them are nouns or noun phrases, which respectively are Birdman(2014), 12 years a slave(2013), Argo(2012), The Artist(2011), The King's Speech(2010), The Hurt Locker(2009), Slum dog Millionaire(2008), No Country for Old Men(2007), The Departed(2006). It is not difficult to discover that nominalization is more and more widely used in English film titles over time.

Standards of Film Titles. A title is the soul of a film. It is the epitome and highlight of the content, which not only attract some potential viewers, but also convince them of further desire to watch it. Therefore an outstanding film title will make the finishing point.

Film title has four functions such as informative function, emotional function, aesthetic function as well as advertisement function (He, 2001:57). To be specific, informative function means prioritizing the content of the movie to enhance a better understanding of it for the audience. Emotional function is for establishing the tone of emotions, attracting and infecting the audience with strong lyrical, thrilling or comic atmosphere. Aesthetic function, that is to create aesthetic enjoyment for viewers by impressing them with elegant and fluent language, or vivid images. Last, to attract viewers and drive the increase in box office sales is so-called advertisement function.

\section{Analysis of the Functions of Nominalization in Film Titles}

The listed 25 Oscar-winning film titles with frequent use of nominalization basically realize the above functions. To begin with, noun or noun phrase form highlights the theme strongly. For example, Titanic, is a name of a luxury liner; Casablanca, a name of a city lying in the north of Morocco; Forrest Gump, a name of a man. It is observed that they are all short enough. As a movie title, they are actually short but never simple. From only a few names, the audience exactly know what takes the center stage. The leading character, the main place or the central identity are all connected with the theme of a movie. Therefore only through these several words, people can easily catch the point of a movie and keep it in mind, which realizes the function of transmitting information.

Besides, nominalization enlarges the amount of information conveyed by the title with the briefest form. Have look at 12 years a slave and Shakespeare in Love. Just from the combination of "12 years" and "slave", a clear image will come to people's mind immediately in which a poor guy has been a slave for almost 12 years. Even some will have a guess that the poor guy probably is a black suffering from discrimination. Through only four words, people can get much more information than the title itself originally convey, and have a general guess of the context of a movie. So it is also a successful and effective realization of information transmitting.

Then some will argue that noun or noun phrase is too pithy without any sentimental color. Here is an example to show it is not true. The Departed was a winner at the 79th Academy Awards, scooping four awards including Best Picture, Best Director, Best Adapted Screenplay and Best Editing. It tells a story of Boston gangster and the police both training undercover agents and assigning them among each other. According to its meaning, "the departed" refers to people who have died. Undoubtedly, a sorrowful feeling will strike people who have a first sight of this title, setting the tone for the movie. So is the realization of emotional function.

Next, is noun or noun phrase too short to bring viewers aesthetic pleasure? A few examples are the best answer. The Hurt Locker is a movie filled with tension and excitement. It is about American soldiers in Iraq whose job is to find and safely destroy hidden explosive devices. It was nominated for as many as nine Academy Awards. Using "the hurt locker" as a title instead of "bomb disposal squad" or other verb phrase indeed provides a more vivid image because their responsibility indeed is to lock hurts for people. Moreover, it stimulates the interest of audience, fulfilling their aesthetic enjoyment. 
If the above three functions can be realized successfully, it is hard to avoid becoming a hit with audience. So as a matter of course, there is no difficulty in attain its advertising purposes. As popular Oscar-winning films, aside from the story itself and actors' brilliant performance, the titles also play an important role and are indispensable for the success of a film.

\section{Conclusion}

In summary, through form analysis and detailed example analysis, it can be found that nominalization is a common form of grammatical metaphor in the title of English film. It can highlight the theme, enlarges the amount of information conveyed by the title with the briefest form, sometimes set the tone for the movie, stimulates the interest of audience and fulfill their aesthetic enjoyment as well. Nominalization successfully achieves the purpose of realizing information transmitting function, emotional function, aesthetic function and advertisement function of film titles, which benefit its promotion and publicity.

So regarding English film titles as a guide, from the perspective of grammatical metaphor, it can be found that nominalization is not a tendency in Chinese mainland film titles. What's more, verb phrase takes up not a small proportion not only in mainland film titles but also Hong Kong and Taiwan film titles while there are few verb phrases in English film titles. Chinese film industry has seen an increasingly development these years. Therefore the need for a good translated film title is more and more important for that as a title for a film, so is eyes to man. Otherwise it will ultimately become uncompetitive on the world market. For Chinese translators, it would be well if they tend to choose nominalization as an expressive way when translate film titles into English. Not only does this make the translation better and easy to remember, but it also makes more and more excellent Chinese films known to foreign people and pushed to the international market, bringing about enormous economic benefit as well as promoting the communication of Chinese and western culture.

\section{Acknowledgement}

This research was financially supported by Humanities and social sciences research project, Hubei Provincial Department of Education (No.2015B247).

\section{References}

[1] Halliday, M.A.M.K. An Introduction to Functional Grammar. London: Edward Arnold Limited, 2000.

[2] Wang Xiaofeng, Zhang Xiyong. "Metaphor in Advertising Language from Systemic Functional Grammar Perspective." Overseas English 10(2012):259-262.

[3] Zhang Delu, Dong Juan. "The Research on Development Patterns of Grammatical Metaphor". Foreign Language Teaching and Research (bimonthly) 1(2014):32-44.

[4] Liu Chenhong. "The Nominalizing Metaphor in News Titles”. Journalism Lover 3(2011):60-61.

[5] Xu Wu, Wu Lingjuan. "On Translation of Scientific and Technical Text from the Perspective of Ideational Metaphor”. Shanghai Journal of Translators 1(2008):38-41.

[6] Chen Long, Li Xiaofeng. "The Application of Ideational Metaphor in Translation of English Film Titles”. Exploration of Language and Words 6(2013):198-200.

[7] Ren Junhua. "The Research on Ideational Metaphor in Translation of Chinese Film Titles". Movie Literature 17(2011):139-140.

[8] He Ying. "The Research on Ideational Metaphor in Translation of Chinese Film Titles". Foreign Language Education 1(2001):56-60. 
[9] Hu Zhuanglin. "Grammatical Metaphor". Foreign Language Teaching and Research 4(1996):1-7.

[10]Zhang Delu, Lei Xi. "The Study of Grammatical Metaphor in China". Foreign Language Education 5(2013):1-6.

[11] Li Beilei, Zhu Ting. "Aesthetics and Creativity: Thoughts on Translation of Chinese Film Titles in Recent Years”. Movie Literature 20(2011):159-160. 